Article

\title{
Fruit Quality and Yield of Three Highbush Blueberry (Vaccinium corymbosum L.) Cultivars Grown in Two Planting Systems under Different Protected Environments
}

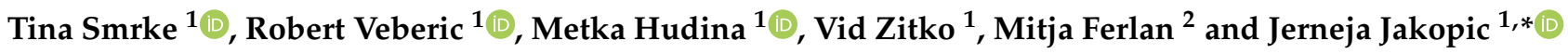 \\ 1 Chair for Fruit Growing, Viticulture and Vegetable Growing, Department of Agronomy, Biotechnical Faculty, \\ University of Ljubljana, SI-1000 Ljubljana, Slovenia; tina.smrke@bf.uni-lj.si (T.S.); \\ robert.veberic@bf.uni-lj.si (R.V.); metka.hudina@bf.uni-lj.si (M.H.); vid.zitko@bf.uni-lj.si (V.Z.) \\ 2 Slovenian Forestry Institute, SI-1000 Ljubljana, Slovenia; mitja.ferlan@gozdis.si \\ * Correspondence: jerneja.jakopic@bf.uni-lj.si; Tel.: +386-1-320-3110
}

check for updates

Citation: Smrke, T.; Veberic, R.; Hudina, M.; Zitko, V.; Ferlan, M.; Jakopic, J. Fruit Quality and Yield of Three Highbush Blueberry (Vaccinium corymbosum L.) Cultivars Grown in Two Planting Systems under Different Protected Environments. Horticulturae 2021, 7, 591. https:/ / doi.org/10.3390/horticulturae7120591

Academic Editor: Esmaeil Fallahi

Received: 1 December 2021

Accepted: 17 December 2021

Published: 20 December 2021

Publisher's Note: MDPI stays neutral with regard to jurisdictional claims in published maps and institutional affiliations.

Copyright: (c) 2021 by the authors. Licensee MDPI, Basel, Switzerland. This article is an open access article distributed under the terms and conditions of the Creative Commons Attribution (CC BY) license (https:/ / creativecommons.org/licenses/by/ $4.0 /)$.

\begin{abstract}
Due to the increasing interest in highbush blueberry (Vaccinium corymbosum L.) among consumers, together with the problems of climate change and specific substrate requirements, a novel approach to intensive blueberry production is required. Here, 'Duke', 'Aurora', and 'Brigitta' blueberry cultivars were planted under the protective environments of a high tunnel and black hail net, each using ridge and pot planting systems. The high tunnel increased the maximal air temperature on average by $7.2^{\circ} \mathrm{C}$ compared to the hail net. For all three cultivars, harvest began 6 to 18 days earlier under the high tunnel than under the hail net; however, lower yields and individual phenolics contents were obtained for the fruit. In 'Aurora' and 'Brigitta', environmental conditions under the high tunnel also reduced plant volume and fruit sugar/organic acid ratio. Growing blueberry plants in $60 \mathrm{~L}$ pots had no negative effects on plant volume and fruit ripening time, yield, firmness, color, and chemical composition. This study represents the first to compare highbush blueberry grown under the high tunnel and hail net protective environments using ridge and pot planting systems across three different cultivars. Here, we can conclude that optimal highbush blueberry production of 'Duke', 'Aurora', and 'Brigitta' under the climate conditions of the study provides earlier ripening times under the high tunnel. However, according to fruit yield and quality, all three cultivars benefit from the hail net over the high tunnel, while 'Duke' and 'Brigitta' also benefit in particular from the hail net combined with growth in pots.
\end{abstract}

Keywords: Vaccinium corymbosum L.; high tunnel; black hail net; ridge; environmental conditions; yield; phenolics

\section{Introduction}

In recent years, consumer demand for blueberry fruit (Vaccinium corymbosum L.) has risen dramatically, due to their favorable sweet and sour taste and their beneficial effects on human health. Together with the high marketable price of the fruit, this has led to a significant increase in blueberry production throughout the world [1,2].

Blueberry fruit contain phenolics (e.g., anthocyanins, flavan-3-ols, flavonols, phenolic acids, hydrolyzing and condensed tannins, and resveratrol), vitamin C, carotenoids, and tocopherols [3,4], all of which provide the health-promoting properties of the fruit, for which blueberry are indicated as a 'functional food' [5]. Previous studies have suggested that long-term consumption of fruit that are rich in phenolics, such as blueberry fruit, has anti-inflammatory effects and provides protection against cancers, cardiovascular diseases, stroke, high blood pressure, diabetes, and osteoporosis [6,7].

Blueberry fruit are now available all year round all over the world. However, the ripening period within individual countries overlaps, which can lower the marketable price of the fruit. The introduction of protected environments into intensive blueberry 
production, such as high tunnels, might represent a solution to this problem. Increased air temperature in the spring can promote faster development of the fruit and thus provide earlier fruit ripening and availability on the market, and consequently a higher price for the fruit earlier in the season, while also avoiding the use of early ripening cultivars that are more sensitive to spring frosts $[2,8]$. Under high tunnels, air temperature, relative air humidity, and light properties differ from those under hail nets, which leads to an earlier occurrence of phenophases. High tunnels can also provide an extended growing season, higher yields, and protection against hail, rain, birds, and frost, which will also allow production to expand toward cooler areas [8]. High tunnels are successfully used today in the production of flowers [9], vegetables [10], and small fruit [11].

In recent years, due to the frequent occurrence of hail storms, the installation of hail nets in blueberry orchards has increased. These protect plants from hail and bird attacks, prevent sunburning of leaves and fruit, and reduce temperature, light, and drought stress of the plants through reduced direct light and increased diffused light reaching the plants [12,13]. Most blueberry growing areas have been described with air temperatures and solar radiation higher compared to their natural habitat. Consequently, hail net introduction into blueberry orchards would be a useful way to bring the environmental conditions in intensive blueberry production closer to those in their natural habitats [14]. In intensive production, black hail nets are most commonly used; however, growing interest in nets of other colors has occurred among growers. Black nets absorb the most light and thus shade the plants the most, while white nets absorb the least. The light that passes through the holes in the black net remains spectrally unchanged, while the light that hits the fibers of other colors scatters and changes spectrally. The modified light spectrum alters plant physiological processes, while scattered light penetrates deeper into the blueberry plant between leaves compared to direct light. The introduction of hail nets has already been established for the production of many fruit species, such as apple [15-17], pear [18], persimmon [19], kiwifruit [20], peach [21], and others, and demand among growers for hail net installation for blueberry orchards has started to appear in recent years [22].

In addition to ridge production of blueberry fruit, pot production represents a new approach with increased interest of growers and researchers in recent years. In particular, this allows the soil $\mathrm{pH}$ to be better controlled through the use of a precise substrate and irrigation and fertilization of the plants. Blueberries thrive in acidic substrates with $\mathrm{pH}$ from 4.5 to 5.5 , which can be very challenging to maintain. Too high a $\mathrm{pH}$ can lead to lower yields, limited growth, and poorer intake of certain nutrients (e.g., iron, manganese, copper) $[2,23]$. Growing blueberries in pots allows the plants to be moved for adjustment of the plant density based on plant volume [24]. The downside of pot production is limited root growth, which reduces the absorption area for water and nutrients. At the same time, the question of the lifespan of plants grown in pots arises: Kingston et al. [25] and Jiang et al. [23] composted pine bark, peat moss, and coconut coir together at $\mathrm{pH} 4.5$, which was reported to be the optimal substrate property for blueberry pot production.

Due to the many difficulties growers have been facing for intensive blueberry production in recent years (e.g., market saturation, hail storms, and substrate $\mathrm{pH}$ ), the interest in alternative production methods has increased. The aim of the present study was to investigate the response of blueberry plants (as plant growth, phenophase occurrence, and fruit quality and yield) under high tunnel and hail net protection with ridge and pot production technologies. At the same time, the air temperatures were monitored, together with relative air humidity, photosynthetic photon flux density, and substrate water content.

\section{Materials and Methods}

\subsection{Experimental Design}

The experiment was conducted in the second year after planting in a test field of the Biotechnical Faculty of Ljubljana University, Ljubljana (Slovenia; latitude, $46^{\circ} 05^{\prime} \mathrm{N}$; longitude, $14^{\circ} 47^{\prime} \mathrm{E}$; altitude, $295 \mathrm{~m}$ a.s.l.). Uniform plants of 'Duke', 'Aurora', and 'Brigitta' were selected on 9 May 2018 and planted in a ridge and in $60 \mathrm{~L}$ pots that were positioned under 
the protected environments of a high tunnel and black hail net (i.e., four treatments for each cultivar and 15-17 plants per treatment of individual cultivar). To provide conditions for optimal pollination, these protected environments were removed (i.e., rolled up on top of the supporting structure) from leaf senescence to the end of flowering.

The high tunnel (Schwarzmann) and hail net supporting structures were $6 \mathrm{~m}$ wide and $24 \mathrm{~m}$ long, with a south to north orientation. The high tunnel was covered with white polypropylene foil (200 $\mu \mathrm{m}$ thickness), with natural ventilation. Four sprinklers (NAAN 501-U; Zeleni hit, Ljubljana, Slovenia) were placed under the high tunnel at a distance of $6 \mathrm{~m}$ from each other, between the ridge and the pots, at $2 \mathrm{~m}$ height. The sprinklers were used from the beginning of July onwards, twice a day, for $2 \mathrm{~h}$ at 11:00 a.m. and 2:00 p.m.

For the ridge and pot planting systems, the plants were positioned at a distance of $0.6 \mathrm{~m}$ along each row and $2 \mathrm{~m}$ between each row. The substrate consisted of peat, soil, and pine sawdust, one-third each by volume. The floor was covered with white polypropylene foil. The plants were also drip irrigated according to sensor measurements (when the substrate water content dropped below $950 \mathrm{mV}$; electrical conductivity), which means different water quantities were applied in each treatment. The plants in a ridge were fertigated once to twice a week, depending on the phenophase $(0.1-0.2 \%)$, and plants in pots every day with smaller concentrations of fertilizer ( $0.03 \%)$, from the beginning of April to mid-June.

\subsection{Environmental Conditions}

Substrate and air temperature, amount of water in the substrate, and relative air humidity were monitored by continuous measurements using substrate temperature sensors (DS18b20; Dallas Semiconductor, Dallas, TX, USA), substrate moisture sensors (EC5; Decagon Devices, Pullman, WA, USA), and air temperature and relative humidity sensors (SHT11 integrated sensor; Sensirion Inc., Staefa, Switzerland), respectively. The data were stored in a measuring instrument and automatically sent to the IoT cloud, which allowed constant access and real-time control of the substrate temperature and water content measurements. Light quality and quantity measurements were made on a clear, sunny day using an illuminance spectrophotometer (250-800 nm; SRI-2000 (FB); Optimum Optoelectronics Corporation, Hsinchu, Taiwan). Measurements were made at $1 \mathrm{~m}$ height under the high tunnel and the hail net, and in the open field, as five repetitions.

\subsection{Plant Volume and Fruit Harvest}

The volume of ten randomly chosen plants was measured on 9 April and 24 October 2019. A measuring tape was used to measured plant height and two widths at half the height (the first in the row direction, the second at $90^{\circ}$ to the row). Plant volumes were calculated according to Equation (1):

$$
\left(\mathrm{V}\left(\mathrm{dm}^{3}\right)=\text { height }(\mathrm{cm}) \times \frac{1}{2} \text { width } 1(\mathrm{~cm}) \times \frac{1}{2} \text { width } 2(\mathrm{~cm}) \times \pi\right) / 1000
$$

The blueberry fruit were harvested every 7 days, starting on 17 June 2019. For each treatment, the plants were harvested from five to eight times, and the dates of every harvest were recorded. At each harvest, the fruit number per plant was counted, and the total yield per plant was measured in the laboratory, together with fruit firmness and peel color. The mean single fruit weight was calculated by dividing the total plant yield by the number of fruit per plant. After the measurements, the fruit were frozen in liquid nitrogen and stored at $-20{ }^{\circ} \mathrm{C}$ for further analysis.

\subsection{Fruit Firmness and Color}

For fruit firmness and color, all of the berries from the same treatment were pooled to provide the average samples. Fifteen randomly chosen berries from across all of the harvests and under each treatment were selected for the measurements. Fruit firmness was 
measured once on each of these fruit using a digital penetrometer (TR; Turin, Italy) with a $1 \mathrm{~mm}$ diameter tip.

The blueberry fruit color was measured using a portable colorimeter (CR-10 Chroma; Konica Minolta, Tokyo, Japan) once on each of the fruit. The parameters used to describe color are $\mathrm{L}^{*}, \mathrm{C}^{*}$, and $\mathrm{h}^{\circ}$ (CIELAB). The $\mathrm{L}^{*}$ (lightness) ranges from 0 to 100 , where 0 is black and 100 is white. The $C^{*}$ provides the chroma, where higher values represent more intense color. The $\mathrm{h}^{\circ}$ (hue angel) represents the color expressed in degrees, from $0^{\circ}$ to $360^{\circ}\left(0^{\circ}\right.$, red; $90^{\circ}$, yellow; $180^{\circ}$, green; $270^{\circ}$, blue).

\subsection{Individual Sugar and Organic Acid Extraction and Determination}

The extraction for the individual sugars and organic acids was carried out using an average sample across all of the harvest dates for all of the treatments, as five repetitions, according to the method previously described by Mikulic-Petkovsek et al. [26]. Freshly thawed fruit were chopped with a knife, and $1 \mathrm{~g}$ homogenous sample was transferred into a test tube with $4 \mathrm{~mL}$ bi-distilled water. The samples were mixed by vortexing and with constant stirring (Unimax 1010 shaker; Heidolph, Schwabach, Germany), with the extraction at room temperature for $30 \mathrm{~min}$. After the extraction, the samples were centrifuged (5810 R; Eppendorf, Hamburg, Germany) at $9000 \times g$ for $10 \mathrm{~min}$ at $4{ }^{\circ} \mathrm{C}$ and transferred into vials through cellulose filters $(0.2 \mu \mathrm{m}$; Chromafil A-20/25; Macherey-Nagel, Düren, Germany). These samples were stored at $-20{ }^{\circ} \mathrm{C}$ until the start of the analysis using high-performance liquid chromatography (HPLC).

For analysis of the individual sugars, the HPLC system (Vanquish; Thermo Scientific, Waltham, MA, USA) was connected to a detector (RI plus; RefractoMax520; Thermo Scientific, Waltham, MA, USA) [27]. These analytical conditions were as follows: column, Rezex RCM-monosaccharide Ca+2\% (300 mm $\times 7.8 \mathrm{~mm}$; Phenomenex, CA, USA); temperature, $65{ }^{\circ} \mathrm{C}$; flow rate, $0.6 \mathrm{~mL} \mathrm{~min}^{-1}$; injection volume, $20 \mu \mathrm{L}$; mobile phase, bi-distilled water; and sample analysis time, $30 \mathrm{~min}$. The individual sugars were identified by comparison of their retention times with corresponding external standards for fructose, glucose, and sucrose (Fluka Chemie GmBH, Buchs, Switzerland) and are expressed as $\mathrm{mg} \mathrm{g}^{-1}$ fresh weight (FW) [27].

Organic acids were analyzed by HPLC (Vanquish system; Thermo Scientific, Waltham, MA, USA) using a Rezex ROA-Organic acid H+ 8\% column (150 mm $\times 7.8 \mathrm{~mm}$; Phenomenex, CA, USA). The UV detector was set at $210 \mathrm{~nm}$ under the following analytical conditions: column temperature, $65^{\circ} \mathrm{C}$; injection volume, $20 \mu \mathrm{L}$; flow rate, $0.6 \mathrm{~mL} \mathrm{~min}{ }^{-1}$; and sample analysis time, $15 \mathrm{~min}$. The mobile phase was $4 \mathrm{mM}$ sulfuric acid in bi-distilled water [27]. The individual organic acids were determined by comparisons with external standards for citric, tartaric, malic, and shikimic acids and are expressed as $\mathrm{mg} \mathrm{g}^{-1} \mathrm{FW}$.

\subsection{Individual Phenolics Extraction and Determination}

Individual phenolics were extracted from the same samples as used for the sugars and organic acids. The freshly thawed fruit were cut into small pieces and finely chopped to obtain a homogenous sample. The precise weight of each sample was recorded for further calculations. Four milliliters of $70 \%$ methanol containing 3\% formic acid in bi-distilled water was added to $2 \mathrm{~g}$ of each fruit sample in test tubes as the extraction solution. The samples were mixed by vortexing, left in a cooled ultrasonic bath $\left(0{ }^{\circ} \mathrm{C}\right)$ for $1 \mathrm{~h}$, and then centrifuged at $9000 \times g$ for $10 \mathrm{~min}$ at $4{ }^{\circ} \mathrm{C}$ (5810 R; Eppendorf, Hamburg, Germany). The supernatant was filtered through $0.2 \mu \mathrm{m}$ polyamide filters (Chromafil AO-20/25; Macherey-Nagel, Düren, Germany), put into vials, and stored at $-20{ }^{\circ} \mathrm{C}$ until further analysis [28].

Separation of the phenolic compounds was on an HPLC system (Dionex UltiMate 3000; Thermo Scientific, Waltham, MA, USA), with detection at absorbances of 280, 350, and $530 \mathrm{~nm}$ under the conditions described by Mikulic-Petkovsek et al. [28] with: flow rate,

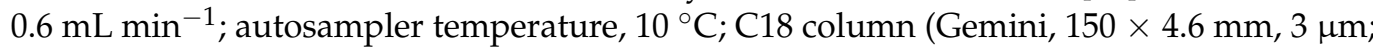
Phenomenex, CA, USA); temperature, $25^{\circ} \mathrm{C}$; and injection volume, $20 \mu \mathrm{L}$. Mobile phase A 
was $3 \%$ acetonitrile and $0.1 \%$ formic acid in bi-distilled water $(v / v / v)$, and mobile phase B was $3 \%$ bi-distilled water and $0.1 \%$ formic acid in acetonitrile $(v / v / v)$. The gradient used was: 0-15 $\mathrm{min}, 5 \% \mathrm{~B}$; 15-20 $\mathrm{min}, 5-20 \% \mathrm{~B}$; 20-30 $\mathrm{min}, 20-30 \%$ B; from, 30-35 min, 30-90\% B; 35-45 $\mathrm{min}, 90-100 \% \mathrm{~B}$; and 45-50 $\mathrm{min}, 100-5 \% \mathrm{~B}$.

The individual phenolic compounds were identified by comparisons of their retention times with external standards and using an ion trap mass spectrometer (LTQ XL linear; Thermo Scientific, Waltham, MA, USA) based on their mass fragmentation patterns. The injection volume of the samples was $10 \mu \mathrm{L}$, and the flow rate was $0.6 \mathrm{~mL} \mathrm{~min}{ }^{-1}$. The mass spectrometer was operated in negative and positive (anthocyanins) ion modes, with electrospray ionization. The capillary temperature was maintained at $250{ }^{\circ} \mathrm{C}$, the sheath gas at 20 units, and the auxiliary gas at 8 units. The source voltage used was $4 \mathrm{kV}$, with $\mathrm{m} / z$ scanning from 115 to 1600 . The phenolic compounds contents were quantified from corresponding external standards and are expressed as $\mathrm{mg} 100 \mathrm{~g}^{-1} \mathrm{FW}$.

\subsection{Statistical Evaluation}

Statistical analysis was performed in R commander i386 4.0.4 (Vienna, Austria) [29]. Statistically significant differences between treatments were determined by one-way analysis of variance (ANOVA). Significant differences between treatments are represented by different letters. Principal component analysis was performed to evaluate how individual treatments are related among each other in terms of the different groups of phenolics.

\section{Results}

\subsection{Environmental Conditions}

As can be seen from Figure 1, there were no differences for the minimum air temperature between the high tunnel and the hail net conditions. However, as the temperature increased, the differences in air temperatures between these two protected environments also increased. The maximum air temperature was considerably higher under the high tunnel, compared to the hail net, with the greatest difference reaching $23{ }^{\circ} \mathrm{C}$ on 26 May 2019. In the warmer months of the year, the maximum air temperature under the high tunnel was $>40{ }^{\circ} \mathrm{C}$ and was once $>50{ }^{\circ} \mathrm{C}$, while under the hail net, the highest measured temperature was $39^{\circ} \mathrm{C}$.
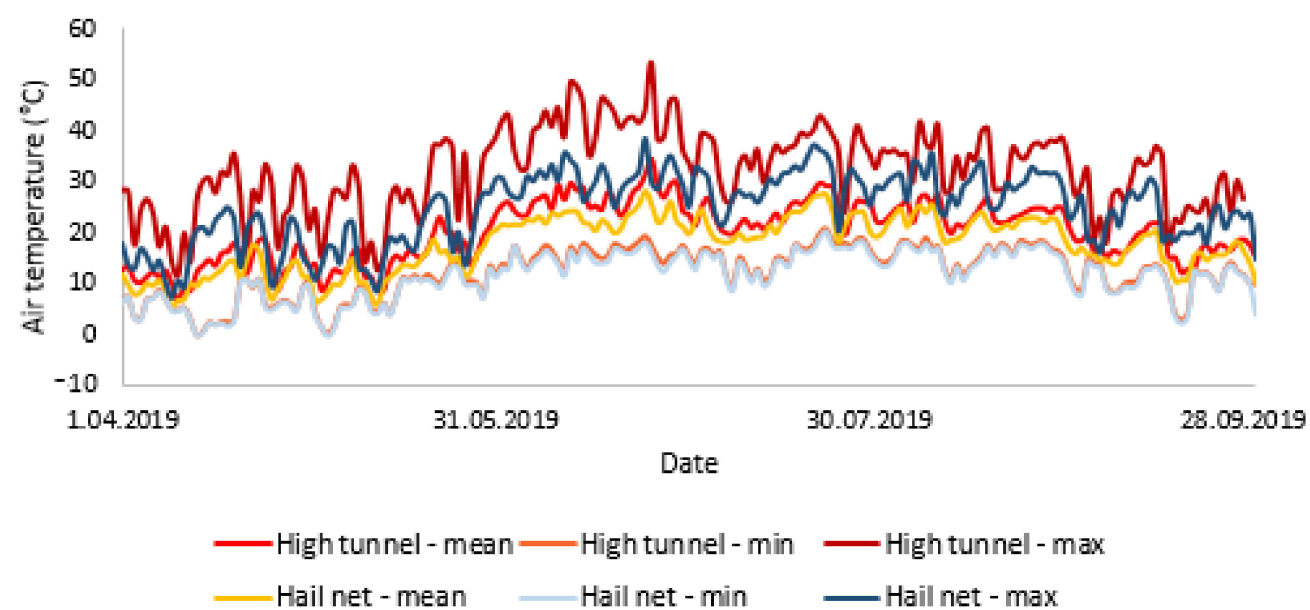

Figure 1. Mean, minimum, and maximum air temperatures under the high tunnel and hail net conditions through the growing season from 1 April to 30 September 2019.

Figure 2 shows the substrate water content (as the electric conductivity) under the high tunnel and hail net for the ridge and pot planting systems. From April to the beginning of June, the different treatments did not differ for the amounts of water made available to the plants. Towards the summer (i.e., from July), the differences became more pronounced, with the highest values under the hail net for the ridge system and the lowest under the high tunnel for the ridge system. For the relative air humidity, this was consistently higher 
under the hail net conditions throughout the measurement period, compared to the high tunnel conditions (Figure 3).

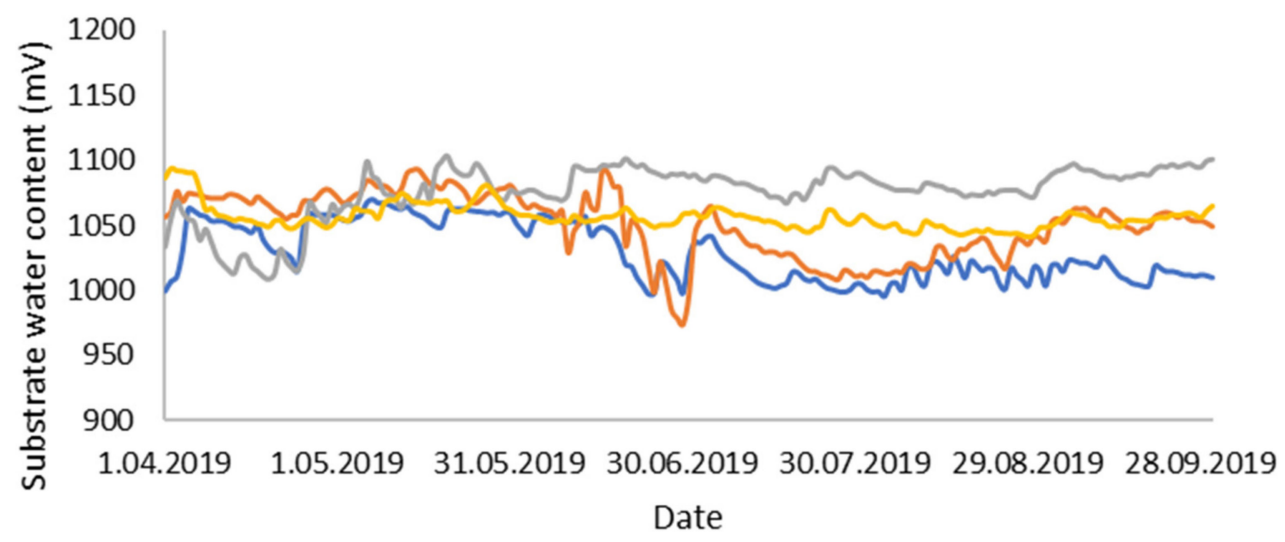

— High tunnel - ridge — High tunnel - pot — Hail net - ridge — Hail net - pot

Figure 2. Substrate water content under the high tunnel and hail net conditions for the ridge and pot planting systems through the growing season from 1 April to 30 September 2019.

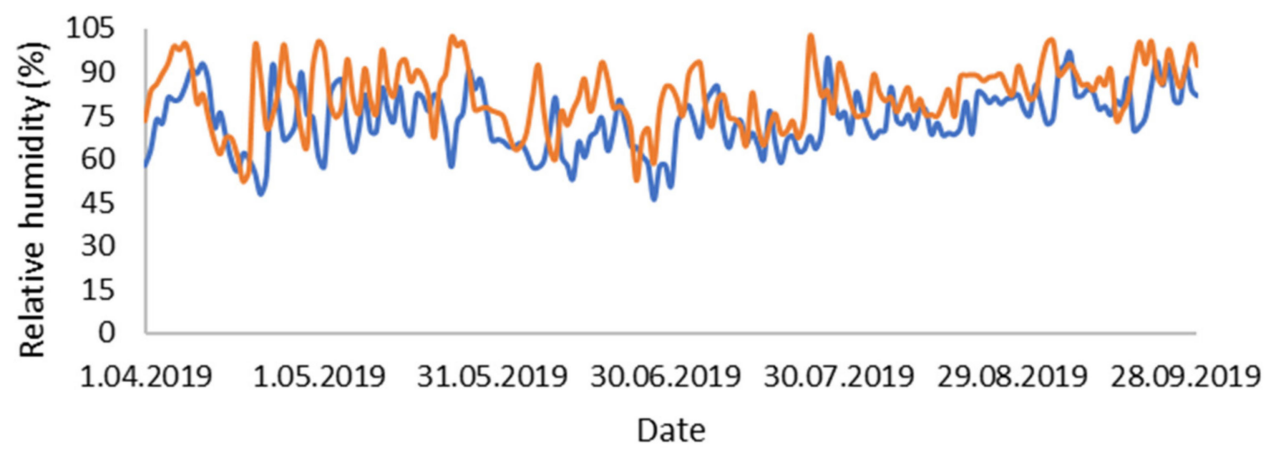

- High tunnel Hail net

Figure 3. Relative air humidity under the high tunnel and hail net conditions through the growing season from 1 April to 30 September 2019.

For the light quantity measurements, compared to the open field $\left(2160.4 \mu \mathrm{mol} \mathrm{m}^{-2} \mathrm{~s}^{-1}\right)$, the high tunnel $\left(1562.5 \mu \mathrm{mol} \mathrm{m}^{-2} \mathrm{~s}^{-1}\right)$ reduced the light quantity by $27.7 \%$ and the hail net $\left(1722.2 \mu \mathrm{mol} \mathrm{m}^{-2} \mathrm{~s}^{-1}\right)$ by $20.3 \%$. Focusing on the UV spectrum (i.e., UV-A, UV-B, and part of UV-C; $250 \mathrm{~nm}$ to $400 \mathrm{~nm}$, based on the device measurement range), the hail net showed higher light quantities compared to the high tunnel.

\subsection{Plant Volume and Yield}

The individual cultivars responded differently to these changed environmental and growth conditions (Table 1). Plant volume in 'Duke' plants differed only between pots; however, no significant differences were measured between high tunnel and hail net and ridge and pots. In 'Aurora', significant differences were seen between all four of the treatments. The highest plant volume in 'Brigitta' was for the plants grown under the hail net, with no significant differences between ridge and pots. Under the high tunnel, the plant volume was significantly higher for the potted plants for 'Brigitta'. For 'Aurora' and 'Brigitta', significantly higher plant volumes were seen under the hail net (when comparing protected environments) and in ridge and pots, respectively (in planting system comparison). 
Table 1. Mean plant volume and yield data for the 'Duke', 'Aurora', and 'Brigitta' cultivars grown under the high tunnel and hail net conditions in the ridge and pots.

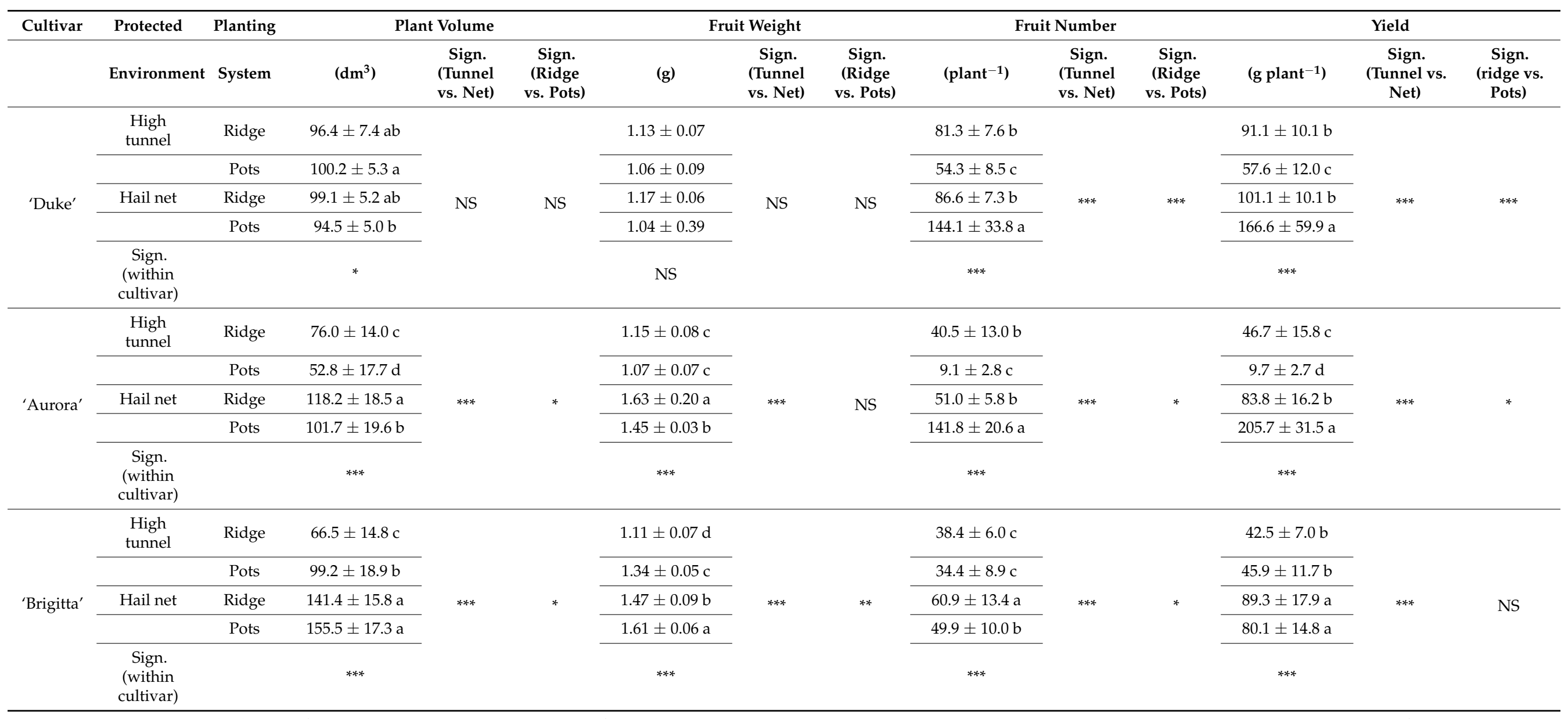

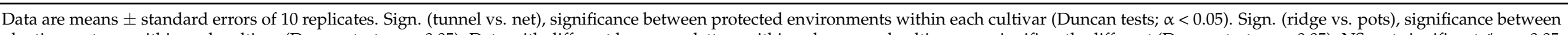

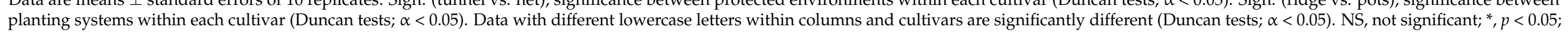
$* *, p<0.01 ; * * *, p<0.001$. 
Fruit from the 'Duke' plants did not significantly differ in weight between treatments (Table 1). 'Aurora' and 'Brigitta' fruit had significantly higher weights when under the hail net. However, fruit from 'Brigitta' were larger from the plants in pots.

Significant differences in fruit number and yield per plant were seen between the treatments for the 'Duke' plants (Table 1). Growing the blueberry plants in pots under the hail net significantly increased the fruit number and yield per plant in 'Aurora', while the lowest values here were seen for the high tunnel with the pots. Production of all three of the cultivars under the high tunnel significantly decreased fruit number and yield per plant, compared to the hail net. For 'Brigitta', significantly higher fruit number per plant was seen for the hail net and in the ridge, although with no significant differences in final yield per plant between ridge and pots.

The dates of the first, peak, and end harvests are given in Table 2. Peak harvest is considered the date with the highest yield. Under the high tunnel, the fruit began to ripen 6 days earlier for 'Brigitta', 9 days earlier for 'Duke', and 18 days earlier for 'Aurora', compared to those under the hail net. However, the peak and end of harvest in 'Aurora' fruit coincided for all treatments, while the difference in ripening dates for 'Duke' remained. Interestingly, the dates of the peak harvest for 'Brigitta' fruit under the high tunnel and hail net differed by 18 days, while the fruit harvest from the different treatments ended on three different dates, over a range of 21 days.

Table 2. Main harvest dates for 'Duke', 'Aurora', and 'Brigitta' cultivars grown under the high tunnel and hail net conditions in the ridge and pots.

\begin{tabular}{cccccc}
\hline \multirow{2}{*}{ Cultivar } & Protected & Planting & \multicolumn{3}{c}{ Harvest } \\
\cline { 2 - 6 } 'Duke' & Environment & System & First & Peak & End \\
\cline { 2 - 6 } & High tunnel & $\begin{array}{c}\text { Ridge } \\
\text { Pots }\end{array}$ & 8 June & 27 June & 8 July \\
\cline { 2 - 6 } & Hail net & $\begin{array}{c}\text { Ridge } \\
\text { Pots }\end{array}$ & 17 June & 2 July & 19 July \\
\cline { 2 - 6 } & High tunnel & $\begin{array}{c}\text { Ridge } \\
\text { Pots }\end{array}$ & 8 July & 5 August & 5 September \\
\cline { 2 - 6 } & Hail net & $\begin{array}{c}\text { Ridge } \\
\text { Pots }\end{array}$ & 26 July & 5 August & 5 September \\
\cline { 2 - 6 } & High tunnel & $\begin{array}{c}\text { Ridge } \\
\text { Pots }\end{array}$ & 21 June & 27 June & 5 August \\
& Hail net & $\begin{array}{c}\text { Ridge } \\
\text { Pots }\end{array}$ & 27 June & 15 July & 5 August \\
& 26 July \\
\hline
\end{tabular}

\subsection{Fruit Firmness and Color}

The blueberry fruit firmness is presented in Table 3. For the 'Duke' and 'Aurora' fruit, no significant differences were seen between the treatments. In contrast, fruit from 'Brigitta' harvested from plants under the high tunnel and in the ridge were significantly firmer, compared to the other three treatments. 
Table 3. Blueberry fruit firmness and peel color for 'Duke', 'Aurora', and 'Brigitta' plants grown under the high tunnel and hail net conditions in the ridge and pots.

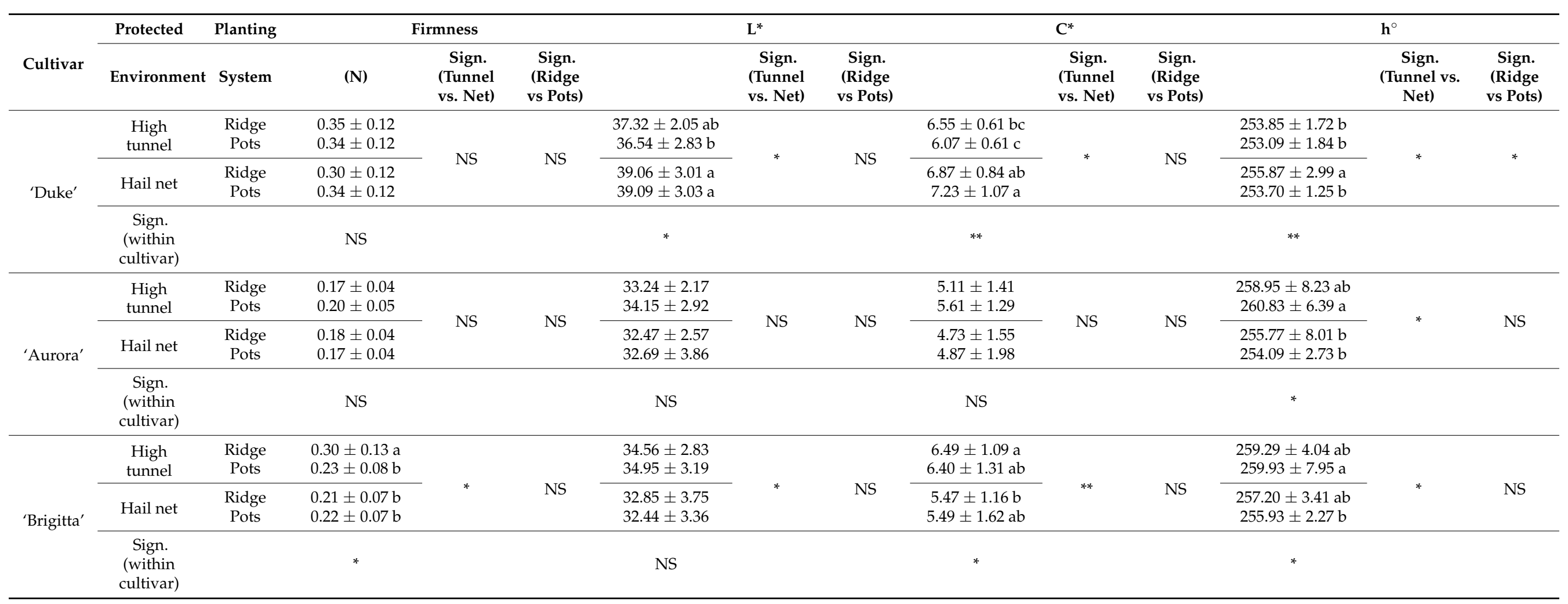

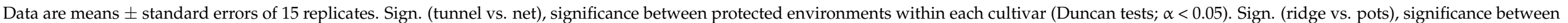

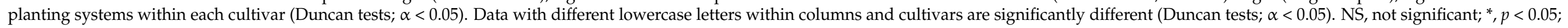
planting syst. 
In 'Duke', significant differences in $L^{*}$ were seen between the fruit under the high tunnel in pots and the fruit under the hail net for both planting systems. There was also a significant difference between the two protected environments and no significant difference between planting systems (Table 3 ). Fruit $L^{*}$ did not significantly differ between treatments for 'Aurora' and 'Brigitta', although significantly higher values were measured for 'Brigitta' fruit from the high tunnel, compared to the pots. Within the 'Duke' cultivar, $\mathrm{C}^{*}$ differed between the high tunnel and hail net fruit across the treatments. At the same time, significant differences were seen for the pots under both protected environments. However, $\mathrm{C}^{*}$ showed no significant differences between the 'Aurora' fruit from the different treatments. Significant opposite differences were seen between the high tunnel and the hail net for the 'Brigitta' fruit compared to the 'Duke', with significant differences also seen between the ridge planting system. Finally, here, significant differences in $\mathrm{h}^{\circ}$ angle were seen across the treatments for all three of the cultivars (Table 3).

\subsection{Total and Individual Sugar Contents}

The changed environmental and growing conditions influenced the fruit total sugar contents within all three of the cultivars (Table 4). 'Duke' showed significantly higher total sugar content for the fruit harvested from plants under the high tunnel and in the ridge, compared to the other three treatments, which showed no significant differences. For the 'Aurora' fruit total sugar content, significant difference was only seen between the high tunnel plants in pots and the hail net plants in the ridge. The same trend was noted for 'Brigitta'; however, significance was also seen between the protected environments and between the high tunnel planting systems. Indeed, the highest value here was for the fruit under the high tunnel and in the ridge, which was approximately twice that of the other treatments. When comparing the high tunnel and the hail net, all three cultivars showed significantly higher total sugar content under the high tunnel, while in the planting systems comparison, 'Duke' and 'Brigitta' showed significantly higher values in fruit from the ridge.

The individual sugar contents for the blueberry fruit are shown in Figure 4. Sucrose content in the 'Duke' fruit significantly differed between all four growing conditions, protected environments, and planting systems. A similar trend for glucose and fructose content was observed, with the highest values under the high tunnel for glucose and under the high tunnel and in the ridge for fructose. However, glucose content did not significnatly differ between protected environments and planting systems. In the 'Aurora' fruit, no significant differences were seen for fruit sucrose content between the plants under the high tunnel and in the ridge and for those under the hail net and in pots; however, there was a significant difference between the high tunnel and the hail net and, at the same time, between the ridge and pots. Glucose content was the same in all of the fruit, while significant differences in fructose content were seen between the treatments under the high tunnel, together with differences between planting systems, with no significance seen between the high tunnel and the hail net. For 'Brigitta', the highest content of all three of these individual sugars was seen for the fruit under the high tunnel and in the ridge and the lowest for the fruit under the hail net. 


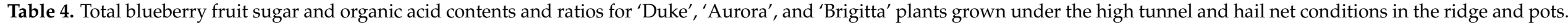

\begin{tabular}{|c|c|c|c|c|c|c|c|c|c|c|c|}
\hline \multirow[t]{2}{*}{ Cultivar } & \multirow{2}{*}{$\begin{array}{c}\text { Protected } \\
\text { Environment }\end{array}$} & \multirow{2}{*}{$\begin{array}{l}\text { Planting } \\
\text { System }\end{array}$} & \multicolumn{3}{|c|}{ Total Sugar Content } & \multicolumn{3}{|c|}{ Total Organic Acid Content } & \multicolumn{3}{|c|}{ Sugar/Organic Acid Ratio } \\
\hline & & & $\left(\mathrm{mg} \mathrm{g}^{-1}\right)$ & $\begin{array}{l}\text { Sign. (Tunnel } \\
\text { vs. Net) }\end{array}$ & $\begin{array}{l}\text { Sign. (Ridge } \\
\text { vs. Pots) }\end{array}$ & $\left(\mathrm{mg} \mathrm{g}^{-1}\right)$ & $\begin{array}{l}\text { Sign. (Tunnel } \\
\text { vs. Net) }\end{array}$ & $\begin{array}{l}\text { Sign. (Ridge } \\
\text { vs. Pots) }\end{array}$ & & $\begin{array}{l}\text { Sign. (Tunnel } \\
\text { vs. Net) }\end{array}$ & $\begin{array}{l}\text { Sign. (Ridge } \\
\text { vs. Pots) }\end{array}$ \\
\hline \multirow{3}{*}{ ‘Duke' } & High tunnel & $\begin{array}{l}\text { Ridge } \\
\text { Pots }\end{array}$ & $\begin{array}{c}92.12 \pm 7.92 \mathrm{a} \\
81.81 \pm 10.83 \mathrm{~b}\end{array}$ & \multirow{2}{*}{ * } & \multirow{2}{*}{ * } & $\begin{array}{c}8.15 \pm 1.84 b \\
10.34 \pm 0.56 a\end{array}$ & \multirow{2}{*}{ NS } & \multirow{2}{*}{$* * *$} & $\begin{array}{l}11.96 \pm 3.48 \mathrm{a} \\
7.95 \pm 1.25 \mathrm{~b}\end{array}$ & \multirow{2}{*}{ NS } & \multirow{2}{*}{$* * *$} \\
\hline & Hail net & $\begin{array}{l}\text { Ridge } \\
\text { Pots }\end{array}$ & $\begin{array}{l}79.47 \pm 7.72 \mathrm{~b} \\
79.85 \pm 2.67 \mathrm{~b}\end{array}$ & & & $\begin{array}{l}8.47 \pm 0.87 \mathrm{~b} \\
9.61 \pm 0.60 \mathrm{a}\end{array}$ & & & $\begin{array}{l}9.45 \pm 1.25 \mathrm{~b} \\
8.34 \pm 0.67 \mathrm{~b}\end{array}$ & & \\
\hline & $\begin{array}{l}\text { Sign. (within } \\
\text { cultivar) }\end{array}$ & & $* *$ & & & $* * *$ & & & $* * *$ & & \\
\hline \multirow{3}{*}{ 'Aurora' } & High tunnel & $\begin{array}{l}\text { Ridge } \\
\text { Pots }\end{array}$ & $\begin{array}{c}59.43 \pm 2.62 \mathrm{ab} \\
61.28 \pm 3.58 \mathrm{a}\end{array}$ & \multirow{2}{*}{$* *$} & \multirow{2}{*}{ NS } & $\begin{array}{l}16.83 \pm 1.79 \mathrm{~b} \\
18.84 \pm 1.24 \mathrm{a}\end{array}$ & \multirow{2}{*}{$* * *$} & \multirow{2}{*}{ NS } & $\begin{array}{l}3.57 \pm 0.40 \mathrm{~b} \\
3.27 \pm 0.28 \mathrm{~b}\end{array}$ & \multirow{2}{*}{$* * *$} & \multirow{2}{*}{ NS } \\
\hline & Hail net & $\begin{array}{l}\text { Ridge } \\
\text { Pots }\end{array}$ & $\begin{array}{c}56.93 \pm 2.48 \mathrm{~b} \\
58.44 \pm 3.44 \mathrm{ab}\end{array}$ & & & $\begin{array}{l}14.16 \pm 2.29 c \\
14.59 \pm 1.93 c\end{array}$ & & & $\begin{array}{l}4.11 \pm 0.65 \mathrm{a} \\
4.06 \pm 0.47 \mathrm{a}\end{array}$ & & \\
\hline & $\begin{array}{l}\text { Sign. (within } \\
\text { cultivar) }\end{array}$ & & * & & & $* * *$ & & & $* * *$ & & \\
\hline \multirow{3}{*}{ 'Brigitta' } & High tunnel & $\begin{array}{l}\text { Ridge } \\
\text { Pots }\end{array}$ & $\begin{array}{l}92.50 \pm 6.33 \mathrm{a} \\
56.24 \pm 7.76 \mathrm{~b}\end{array}$ & \multirow{2}{*}{$* * *$} & \multirow{2}{*}{ * } & $\begin{array}{l}8.22 \pm 0.53 b \\
9.29 \pm 0.78 \mathrm{a}\end{array}$ & \multirow{2}{*}{ NS } & \multirow{2}{*}{ NS } & $\begin{array}{c}11.30 \pm 1.14 \mathrm{a} \\
6.11 \pm 1.08 \mathrm{~b}\end{array}$ & \multirow{2}{*}{$* * *$} & \multirow{2}{*}{$*$} \\
\hline & Hail net & $\begin{array}{l}\text { Ridge } \\
\text { Pots }\end{array}$ & $\begin{array}{l}39.77 \pm 2.98 \mathrm{c} \\
42.84 \pm 1.02 \mathrm{c}\end{array}$ & & & $\begin{array}{l}9.19 \pm 1.00 \mathrm{a} \\
8.19 \pm 0.40 \mathrm{~b}\end{array}$ & & & $\begin{array}{l}4.38 \pm 0.62 \mathrm{~d} \\
5.24 \pm 0.26 \mathrm{c}\end{array}$ & & \\
\hline & $\begin{array}{l}\text { Sign. (within } \\
\text { cultivar) }\end{array}$ & & $* * *$ & & & $* * *$ & & & $* * *$ & & \\
\hline
\end{tabular}

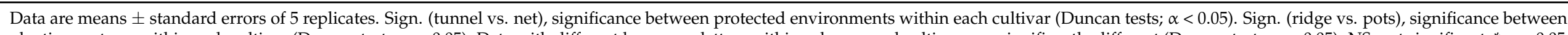

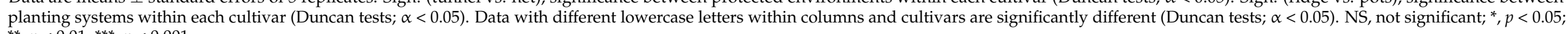
${ }_{* *}^{* *} p<0.01 ; * * *, p<0.001$. 

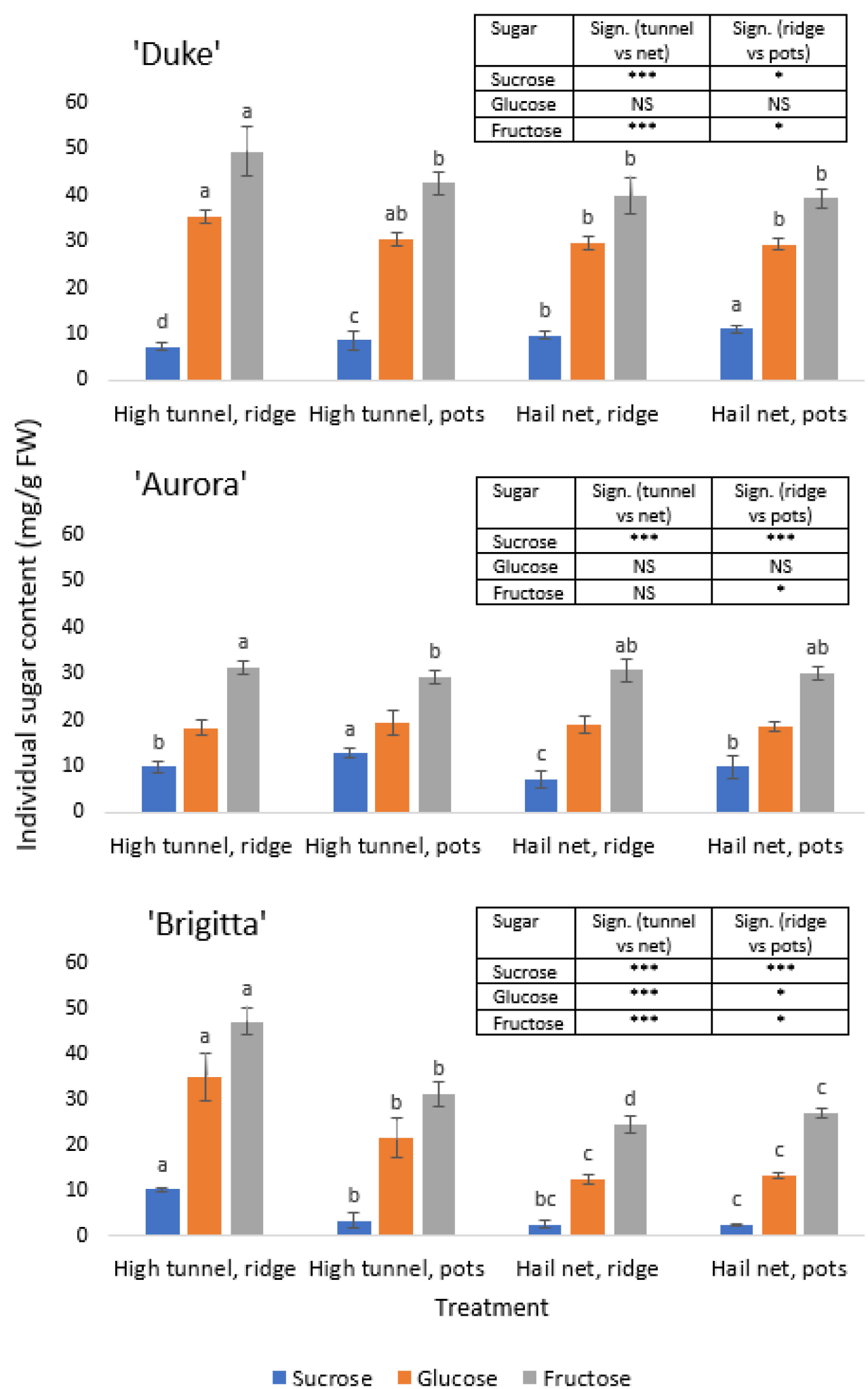

Figure 4. Blueberry fruit sucrose, glucose, and fructose contents for 'Duke', 'Aurora', and 'Brigitta' plants grown under the high tunnel and hail net conditions in the ridge and pots. Different letters indicate statistically significant differences between treatments for individual sugars. Sign. (tunnel vs. net), significance between protected environments within each cultivar (Duncan tests; $\alpha<0.05$ ). Sign. (ridge vs. pots), significance between planting systems within each cultivar (Duncan tests; $\alpha<0.05$ ). NS, not significant; ${ }^{*}, p<0.05 ;{ }^{* * *}, p<0.001$ (Duncan test, $\alpha<0.05$ ). 


\subsection{Total and Individual Organic Acid Contents}

The total organic acids content in 'Duke' was highest for the fruit from the pots, with no significant differences between the high tunnel and the hail net (Table 4); however, significance was noted between the ridge and pots. Similar data were seen for the 'Aurora' fruit, where the highest total organic acids content was for the fruit under the high tunnel and in pots and the lowest was for the fruit under the hail net. At the same time, the fruit from the high tunnel showed significantly higher total organic acids content compared to the hail net. For the 'Brigitta' fruit here, no significant differences were seen between the high tunnel and the hail net, nor between the ridge and pots.

The individual organic acids contents in the blueberry fruit are shown in Figure 5. Here, significant differences were seen in all four of the organic acids identified in all three of the cultivars, with no particular trends in favor of any individual treatment. Citric acid was the predominant organic acid, and in 'Duke', it was significantly higher for the fruit from the pots, compared to the ridge. However, no significant differences were seen between the high tunnel and the hail net for citric acid for 'Duke'. For 'Aurora', citric and malic acid contents were lowest for the fruit from the hail net, as for tartaric acid content from the plants under the hail net and in pots. For the high tunnel and hail net comparison, the highest contents for all of the organic acids identified were for the fruit from the high tunnel. The 'Brigitta' fruit contained the highest citric and tartaric acid contents for the plants under the high tunnel and in pots and for those under the hail net and in the ridge. Here, the highest malic acid content was for the fruit under the high tunnel and in pots, and the shikimic acid content was highest for the fruit under the hail net. Considering different planting systems, no significance was observed in individual organic acid contents.

\subsection{Sugar/Organic Acid Ratio}

From the data given in Table 4, it can be seen that for the total sugar/organic acid ratio, each cultivar responded differently to the different growing conditions. For 'Duke', the highest total sugar/organic acid ratio was seen for the fruit under the high tunnel and in the ridge, and for 'Aurora', for the fruit under the hail net. For 'Brigitta', significant differences for the total sugar/organic acid ratio were seen between all of the treatments, with the highest for the fruit under the high tunnel and in the ridge and the lowest for the fruit under the hail net and in pots, with a corresponding significant difference when comparing protected environments or planting systems.

\subsection{Phenolics Content}

The individual phenolics contents in 'Duke' fruit are shown in Figure 6, with additional statistical analysis in Supplementary Material Table S1. The highest individual phenolics content was for fruit from under the hail net and in pots, and the lowest was for the high tunnel. For the high tunnel, no significant differences were seen for most of the phenolics identified in the fruit across the different planting systems. According to the statistical analysis, some exceptions were noted among the phenolic acids, flavan-3-ols, and anthocyanins. At the same time, significance was detected in total phenolic acids and flavan-3-ols content between the ridge and pots. 


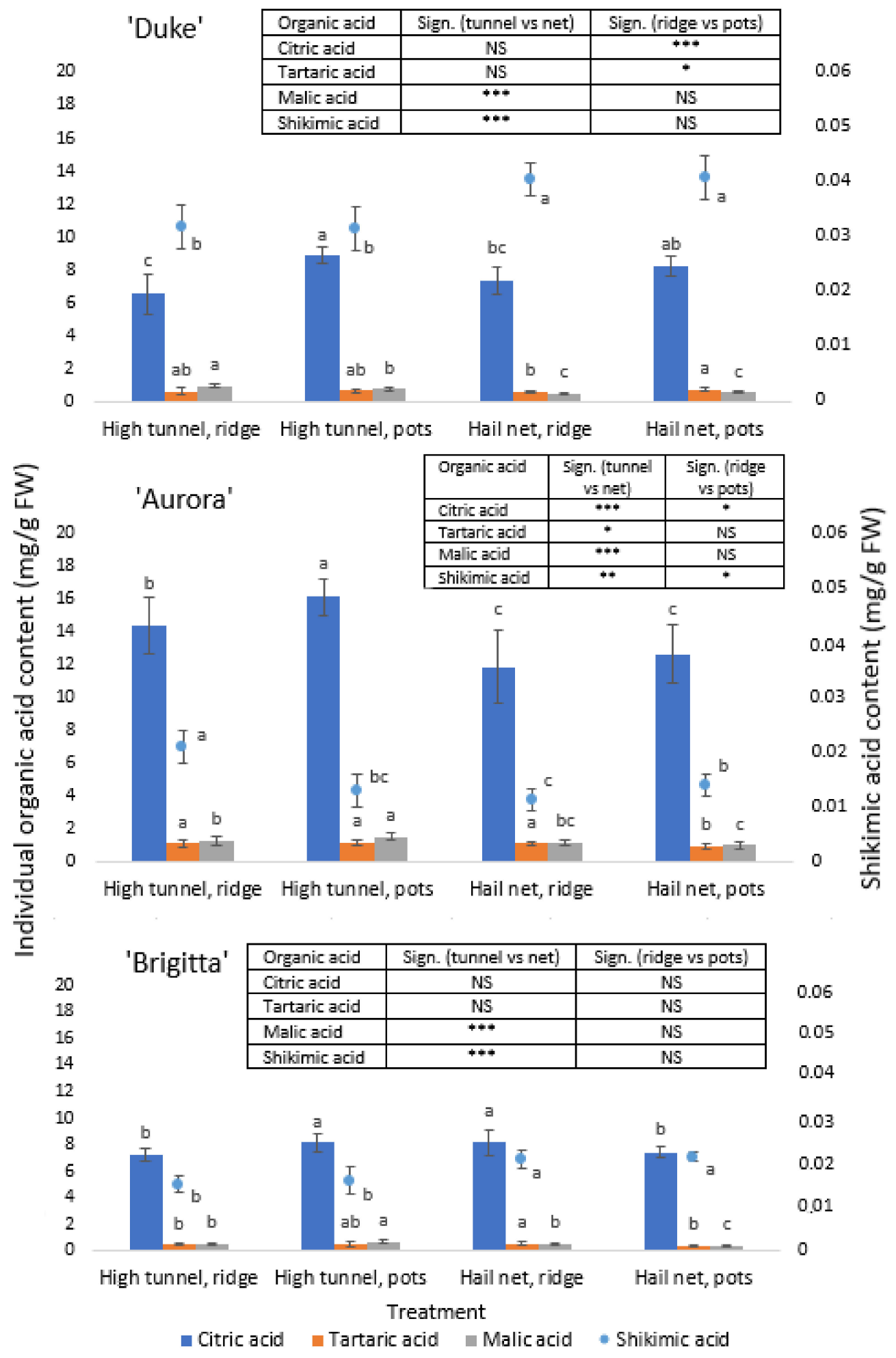

Figure 5. Blueberry fruit citric, tartaric, malic, and shikimic acid contents for 'Duke', 'Aurora', and 'Brigitta' plants grown under the high tunnel and hail net conditions in the ridge and pots. Different letters indicate statistically significant differences between treatments for individual organic acids. Sign. (tunnel vs. net), significance between protected environments within each cultivar (Duncan tests; $\alpha<0.05$ ). Sign. (ridge vs. pots), significance between planting systems within each cultivar (Duncan tests; $\alpha<0.05$ ). NS, not significant; ${ }^{*}, p<0.05 ;{ }^{* *}, p<0.01 ;{ }^{* * *}, p<0.001$ (Duncan test, $\alpha<0.05)$. 


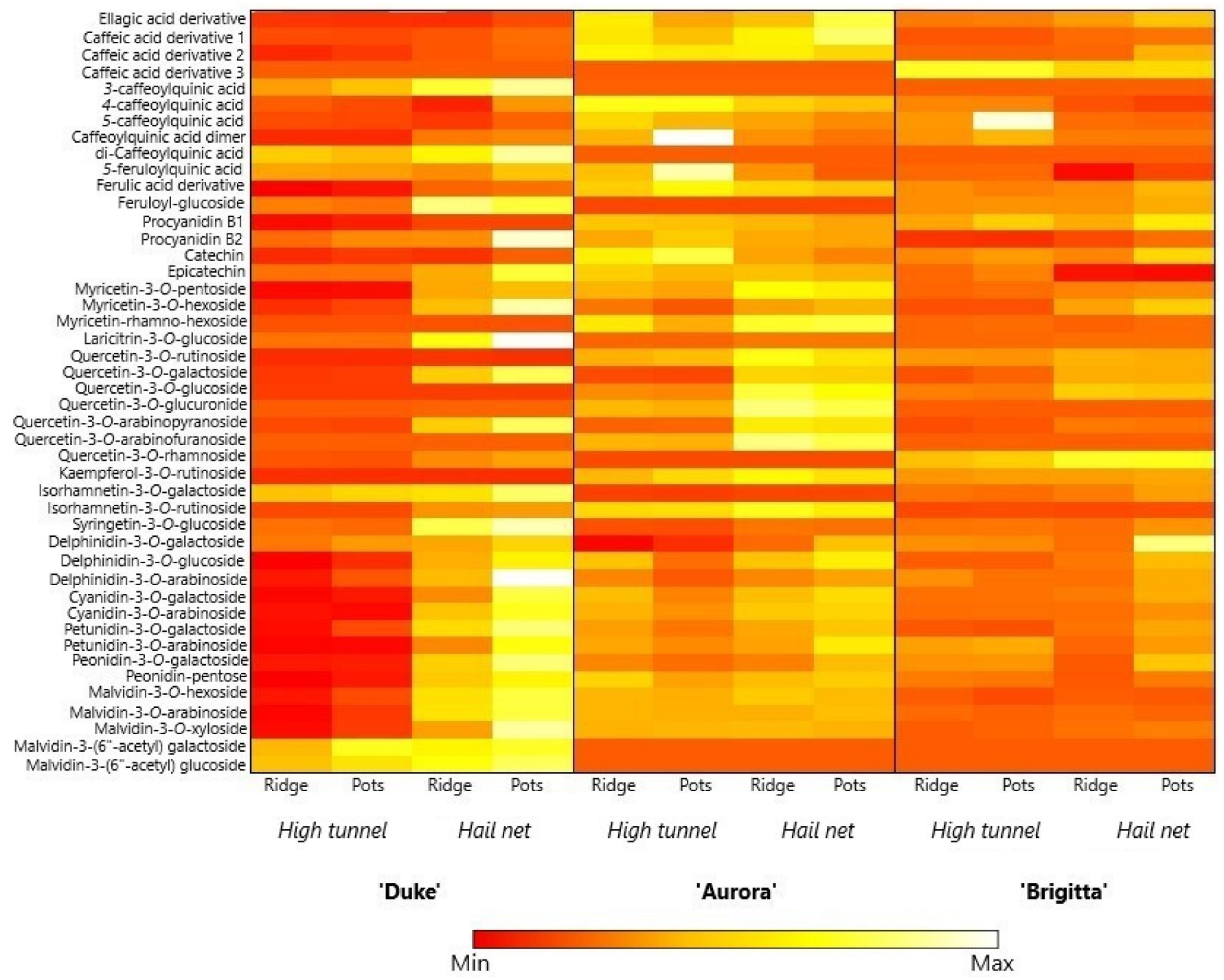

Figure 6. Heatmap for blueberry fruit individual phenolics contents for 'Duke', 'Aurora', and 'Brigitta' plants grown under the high tunnel and hail net conditions in the ridge and pots.

The highest individual phenolics contents for phenolic acids and flavan-3-ols identified in 'Aurora' varied between the treatments; however, their total content was highest under the high tunnel (Figure 6; Supplementary Material Table S2). The opposite was seen for flavonols, where the highest content of all of these compounds was for the fruit under the hail net, which were in most cases independent of the planting system. The exceptions here were quercetin-3-O-arabinofuranoside, kaempferol-3-O-rutinoside, isorhamnetin-3O-rutinoside, and syringetin-3-O-glucoside, where the highest contents were seen for the fruit from the plants in the ridge. As far as the anthocyanins are concerned, a similar trend was seen for flavonols, with the highest contents for the fruit under the hail net and in pots, with some exceptions (i.e., cyanidin-3-O-arabinoside, peonidin-pentose, and malvidin derivatives).

Focusing on 'Brigitta', the data are not in favor of any one or other of the treatments (Figure 6). Among the phenolic acids, an ellagic acid derivative, caffeic acid derivatives 1 and 2, and feruloyl-glucoside contents were the highest for the fruit harvested under the hail net from the plants in pots (see Supplementary Material Table S3). The contents of procyanidin B1 and B2 and catechin were the highest for the fruit under the hail net and in pots; on the contrary, the epicatechin content was highest for the fruit under the high tunnel. This corresponds to the total phenolic acids and flavan-3-ols contents comparison between planting systems, where significantly higher values were measured in pots. Then, 
for the flavonol group, the highest contents of most of these compounds were seen for the fruit from under the hail net, and for the anthocyanin group, for the fruit under the hail net and in pots.

The principal component analysis carried out for the individual groups of phenolics (Figure 7) suggests that 'Duke' fruit from under the high tunnel contained lower contents of all of the phenolics. At the same time, the contents were in favor of the pots. A large clustering of 'Aurora' and 'Brigitta' was seen, with higher contents in 'Aurora'. For total phenolics content, the same trend was seen as for 'Duke', with the higher content for the fruit from under the hail net.

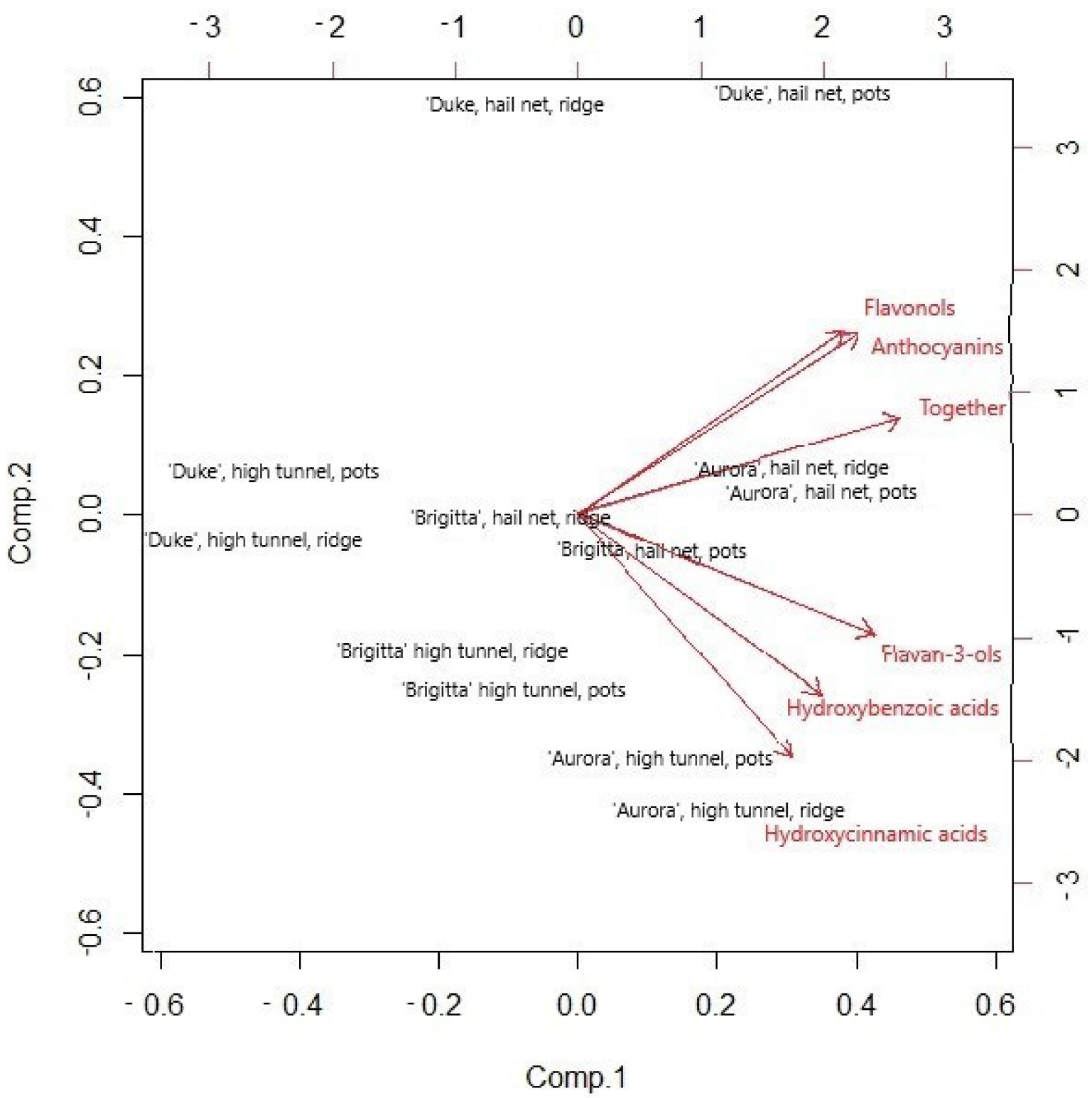

Figure 7. Principal component analysis of the blueberry fruit contents for the individual groups of phenolics for 'Duke', 'Aurora', and 'Brigitta' plants grown under the high tunnel and hail net conditions in the ridge and pots.

Correlation tests showed strong correlation between all of the phenolics groups and the total phenolics content, except for hydroxycinnamic and hydroxybenzoic acids. Strong correlation was also seen between anthocyanins and flavonols content $(p<0.0001)$. 


\section{Discussion}

To date, only a few studies have compared highbush blueberry production under the protected environments of a high tunnel and a hail net. Furthermore, no studies have yet compared these together with the ridge and pot planting systems and their connection with the environmental conditions. In the present study, the air temperature under the high tunnel reached higher values compared to those under the hail net, which is in agreement with some previous reports from studies conducted under high tunnels [8,30-32]. The maximum air temperature under the high tunnel during the fruit ripening period reached values above the individual cultivar thresholds for photosynthesis. According to Moon et al. [33], the 'Jersey' photosynthesis threshold is between $18{ }^{\circ} \mathrm{C}$ and $26{ }^{\circ} \mathrm{C}$, and for 'Bluecrop', between $14{ }^{\circ} \mathrm{C}$ and $22^{\circ} \mathrm{C}$. These thresholds suggest that high air temperatures during the summer can lead to heat stress in plants under a high tunnel, which will result in reduced photosynthesis and, consequently, limited metabolite accumulation [34].

From the beginning of July onwards, the differences in maximum air temperature between the high tunnel and the hail net were not so large, due to the use of micro sprinklers under the high tunnel, which will reduce the air temperature and cool down the plants. Together with drip irrigation, the micro sprinklers provided the plants with an adequate water supply; however, the substrate water content was still higher under the hail net, due to natural precipitation. The larger substrate volume in the ridge under the hail net led to higher water contents. The opposite was seen under the high tunnel, where in the warmer months of the year, uneven water distribution from the micro sprinklers led to higher water contents in the pots. The lower relative air humidity that was measured under the high tunnel might be a result of the higher air temperature and, consequently, lower leaf stomatal conductivity [35], which is in agreement with a previous report by Retamal-Salgado et al. [30].

The individual cultivars responded differently to the changed growing conditions, which is evident from the plant volume and yield measures. This suggests the interdependence of genetics and the environment in plant responses to modified growing conditions [32,36]. From the plant volumes and yields for 'Duke' and 'Brigitta', we can conclude that the substrate volume in the pots was comparable to that in the ridge, where there was no restriction to root system development, and consequently, water absorption through the roots occurred. At the same time, the substrate content in the pots was not the limiting factor in these young plants. With the adequate water supply, equally intense growth and yields were seen for the plants in the ridge and in the pots, with the exception of the yield in 'Duke' grown under the high tunnel. The results also show a reverse relationship between plant volume and fruit number per plant for 'Duke'. Cantliffe [37] also stated that the growth of roots and shoots increases as the pot volume increases. On the other hand, 'Aurora' appears to be more sensitive to the changes in the environmental conditions (i.e., protected environment, planting method) for both plant volume and yield. Together with 'Brigitta', their plant volume and yield were significantly lower under the high tunnel compared to the hail net, as also seen in some previous reports [32,34]. The plant volumes were limited because the optimal substrate temperature for blueberry plant growth is from $14{ }^{\circ} \mathrm{C}$ to $18^{\circ} \mathrm{C}$, which was strongly exceeded during the growing season under the high tunnel, where it reached $30^{\circ} \mathrm{C}$ in the ridge and $33^{\circ} \mathrm{C}$ in the pots [2]. According to Yang et al. [38], the air temperature range for the optimal fruit setting is $15^{\circ} \mathrm{C}$ to $25^{\circ} \mathrm{C}$, which in the present study was exceeded under the high tunnel, as was clearly seen from the individual fruit weight measurements. At the same time, the high temperatures and low relative air humidities seen for the present study can reduce fruit expansion, due to increased transpiration of the fruit [39]. Opposite results were reported by Retamal-Salgado et al. [30], who measured a $44 \%$ higher yield under a high tunnel compared to a hail net. According to Santos and Salame-Dinoso [40], this might result from the increased minimum air temperature under the protected environment; however, this was not the case in the present study. Many native blueberries grow in the shade, and therefore intensive production under full lighting is likely to subject the plants to radiation and temperature 
stress. The use of a high tunnel or a hail net reduces the amount of light reaching the plants, which will reduce the stress and allow better growth and higher yields [14]. However, based on previous reports, the growth and yield strongly depend on the latitude [14,41].

A high tunnel modifies the environmental conditions and consequently promotes fruit ripening [30], as demonstrated in the present study. Our results coincide with those reported by Retamal-Salgado et al. [30] and Tamada and Ozeki [32], who reported about 14 days and 7 days to 40 days earlier fruit ripening, respectively, under a high tunnel and for 12 different cultivars.

Fruit firmness is among the main indicators of blueberry fruit quality [42], which mainly depends on the ripening stage and environmental conditions [36,43]. The firmness here differed only for the 'Brigitta' fruit, where firmer fruit were seen for the plants under the high tunnel and in the ridge. Ehlenfeldt and Marin [43] reported significant interactions between harvest year and cultivar, thereby confirming the dependence of fruit firmness on the environmental conditions.

Together with fruit size and firmness, a dark blue/violet peel color for blueberry fruit is a key parameter that makes the fruit intriguing to the consumer [44]. The key regulating factor of blueberry peel color is the amount of light [2], whereby a higher light quantity leads to a more intense peel color [19]. Although significant differences in the fruit color parameters were seen for the individual cultivars here, these differences were minor and were not possible to detect with the naked eye.

Sugar and organic acid contents are the fruit properties that determine the fruit quality and whether the fruit will be appreciated by the consumer [45]. These contents are strongly correlated with the cultivar and ripening stage [44,46,47], together with environmental conditions, such as light quantity and air temperature [31]. The changes in the sugars and organic acids during ripening are a result of synthesis, degradation, and translocation [46]. In the present study, three individual sugars were identified in the blueberry fruit: fructose, glucose, and sucrose. Fructose contributed the most to the total sugar content, as the prevailing sugar, which is clearly seen from similar statistical analysis and the significant differences across all three of the cultivars. For 'Duke', no significant differences were seen for fruit weight between the treatments, with no differences also seen for total sugar content and sugar/organic acid ratio, with the exception of the plants under the high tunnel and in the ridge.

As the predominant organic acid, citric acid is responsible for the higher total organic acids in the fruit from the plants in pots. A moderate organic acid content makes the fruit more palatable, while a high organic acid content reduces fruit quality [46]. 'Aurora' is generally known for its acidic taste, due to its high organic acid content [48]. Growth under the high tunnel increased the citric acid here and, consequently, the total organic acid content, which affected the sugar/organic acid ratio. This might result from lower substrate water content and fruit weight compared to the hail net [49]. In 'Brigitta', with the highest total sugar content and sugar/organic acid ratio in the fruit under the high tunnel and in the ridge, this suggests that the high sugar concentration is due to lower substrate water content and, consequently, lower fruit weight. This is in agreement with some previous studies, where an induced water deficit significantly reduced fruit weight and increased soluble solids in 'Elliot' and 'Brigitta' [49,50].

A high phenolic compounds content is desirable in blueberry fruit, as they can be beneficial for human health. The largest contribution to the total phenolics content was from the anthocyanins, due to their high content in the blueberry fruit [1]. Consequently, it is not surprising that the analysis of the anthocyanins generally parallels that of the total phenolics. The plants under the hail net were exposed to higher light quantity, and consequently the fruit from all three of the cultivars, especially 'Duke', contained significantly higher individual phenolics contents compared to the high tunnel. The higher UV radiation that was measured under the hail net is known to accelerate flavonol and anthocyanin synthesis [51], which is once more shown in the present study for all three cultivars. At the same time, higher air temperatures under the high tunnel probably limited 
photosynthesis, which leads to reduced metabolite synthesis [33,34]. Higher phenolic acids in 'Aurora' fruit from pots are in accordance with our previously reported results [52] and could be a consequence of more pronounced substrate temperature fluctuations, which causes stress in plants [53].

\section{Conclusions}

Despite earlier fruit ripening, growing blueberry plants under a high tunnel has been shown not to be a suitable method for intensive blueberry production in the climate investigated here. The modified environmental conditions under the high tunnel have negative effects on blueberry plant and fruit performance, which is reflected in lower plant volume, fruit yield, and phenolics content. From the comparison of the ridge and pot planting systems, we can conclude that $60 \mathrm{~L}$ pots more than satisfied the needs of the plants for water uptake and optimal root development and can be a suitable planting system for young plants, as there were no negative effects on plant volume and fruit yield, firmness, color, and chemical composition. Growing the plants under the hail net positively affected plant growth, fruit yield, and phenolics content; however, ripening occurred earlier under the high tunnel. At the same time, higher sugar/organic acid ratios were seen for the 'Brigitta' fruit under the high tunnel. This is the first investigation that has compared highbush blueberry plants grown under a high tunnel and a hail net using ridge and pot planting systems. Despite the promising data, further studies are required, particularly to evaluate the plant volume, fruit yield, and chemical composition over several years using the above-described production technologies.

Supplementary Materials: The following are available online at https:/ / www.mdpi.com/article/ 10.3390/horticulturae7120591/s1, Table S1: Blueberry fruit individual phenolics contents for the 'Duke' cultivar grown under the high tunnel and hail net conditions in the ridge and pots. Table S2: Blueberry fruit individual phenolics contents for the 'Aurora' cultivar grown under the high tunnel and hail net conditions in the ridge and pots. Table S3: Blueberry fruit individual phenolics contents for the 'Brigitta' cultivar grown under the high tunnel and hail net conditions in the ridge and pots.

Author Contributions: Conceptualization, T.S, R.V. and J.J.; methodology, M.F. and J.J.; formal analysis, T.S. and V.Z.; investigation, T.S.; resources, M.H.; data curation, T.S. and V.Z.; writingoriginal draft preparation, T.S.; writing-review and editing, R.V., M.H. and J.J.; visualization, T.S.; supervision, R.V. and J.J.; project administration, R.V. and J.J.; funding acquisition, M.H. All authors have read and agreed to the published version of the manuscript.

Funding: The authors acknowledge the financial support of the Slovenian Research Agency within the research program Horticulture (P4-0013).

Data Availability Statement: The data presented in this study are available on request from the corresponding author. The data are not publicly available due to privacy.

Conflicts of Interest: The authors declare no conflict of interest.

\section{References}

1. Grace, M.H.; Xiong, J.; Esposito, D.; Ehlenfeldt, M.; Lila, M.A. Simultaneous LC-MS quantification of anthocyanins and nonanthocyanin phenolics from blueberries with widely divergent profiles and biological activities. Food Chem. 2019, 277, 336-346. [CrossRef]

2. $\quad$ Retamales, J.B.; Hancock, J.F. Blueberries, 2nd ed.; Cabi: Boston, MA, USA, 2018.

3. Barberis, A.; Spissu, Y.; Fadda, A.; Azara, E.; Bazzu, G.; Marceddu, S.; Angioni, A.; Sanna, D.; Schirra, M.; Serra, P.A. Simultaneous amperometric detection of ascorbic acid and antioxidant capacity in orange, blueberry and kiwi juice, by a telemetric system coupled with a fullerene- or nanotubes-modified ascorbate subtractive biosensor. Biosens. Bioelectron. 2015, 67, 214-223. [CrossRef]

4. Bunea, A.; Rugină, D.; Pintea, A.; Andrei, S.; Bunea, C.; Pop, R.; Bele, C. Carotenoid and fatty acid profiles of bilberries and cultivated blueberries from Romania. Chem. Pap. 2012, 66, 935-939. [CrossRef]

5. Huang, W.Y.; Zhang, H.C.; Liu, W.X.; Li, C.Y. Survey of antioxidant capacity and phenolic composition of blueberry, blackberry, and strawberry in Nanjing. J. Zhejiang Univ. Sci. B 2012, 13, 94-102. [CrossRef]

6. Jennings, A.; Welch, A.A.; Spector, T.; Macgregor, A.; Cassidy, A. Intakes of anthocyanins and flavones are associated with biomarkers of insulin resistance and inflammation in women. J. Nutr. 2014, 144, 202-208. [CrossRef] [PubMed] 
7. Curtis, P.J.; Van Der Velpen, V.; Berends, L.; Jennings, A.; Feelisch, M.; Umpleby, A.M.; Evans, M.; Fernandez, B.O.; Meiss, M.S.; Minnion, M.; et al. Blueberries improve biomarkers of cardiometabolic function in participants with metabolic syndrome-results from a 6-month, double-blind, randomized controlled trial. Am. J. Clin. Nutr. 2019, 109, 1535-1545. [CrossRef]

8. Li, T.; Bi, G. Container production of southern highbush blueberries using high tunnels. HortScience 2019, 54, 267-274. [CrossRef]

9. Owen, G.W.; Hilligoss, A.; Lopez, R.G. Late-season high tunnel planting of specialty cut flowers in the midwestern United States influences yield and stem quality. Horttechnology 2016, 26, 338-343. [CrossRef]

10. Janke, R.R.; Altamimi, M.E.; Khan, M. The Use of High Tunnels to Produce Fruit and Vegetable Crops in North America. Agric. Sci. 2017, 08, 692-715. [CrossRef]

11. Demchak, K.; Hanson, E.J. Small fruit production in high tunnels in the US. Acta Hortic. 2013, 987, 41-44. [CrossRef]

12. Lobos, G.A.; Retamales, J.B.; Hancock, J.F.; Flore, J.A.; Cobo, N.; del Pozo, A. Spectral irradiance, gas exchange characteristics and leaf traits of Vaccinium corymbosum L. "Elliott" grown under photo-selective nets. Environ. Exp. Bot. 2012, 75, 142-149. [CrossRef]

13. Solomakhin, A.; Blanke, M. The microclimate under coloured hailnets affects leaf and fruit temperature, leaf anatomy, vegetative and reproductive growth as well as fruit colouration in apple. Ann. Appl. Biol. 2010, 156, 121-136. [CrossRef]

14. Lobos, G.A.; Retamales, J.B.; Hancock, J.F.; Flore, J.A.; Romero-Bravo, S.; Del Pozo, A. Productivity and fruit quality of Vaccinium corymbosum cv. Elliott under photo-selective shading nets. Sci. Hortic. 2013, 153, 143-149. [CrossRef]

15. Iglesias, I.; Alegre, S. The effect of anti-hail nets on fruit protection, radiation, temperature, quality and probability of Mondial Gala apples. J. Appl. Hortic. 2006, 08, 91-100. [CrossRef]

16. Jakopic, J.; Veberic, R.; Stampar, F. The effect of reflective foil and hail nets on the lighting, color and anthocyanins of "Fuji" apple. Sci. Hortic. 2007, 115, 40-46. [CrossRef]

17. Jakopic, J.; Stampar, F.; Veberic, R. Influence of hail net and reflective foil on cyanidin glycosides and quercetin glycosides in "Fuji" apple skin. HortScience 2010, 45, 1447-1452. [CrossRef]

18. Kiprijanovski, M.; Gjamovski, V.; Arsov, T. The effects of anti-hail net in protection of pear orchard after hailstorm occurrence. Acta Hortic. 2016, 1139, 529-534. [CrossRef]

19. Smrke, T.; Persic, M.; Veberic, R.; Sircelj, H.; Jakopic, J. Influence of reflective foil on persimmon (Diospyros kaki Thunb.) fruit peel colour and selected bioactive compounds. Sci. Rep. 2019, 9, 19069. [CrossRef]

20. Basile, B.; Giaccone, M.; Cirillo, C.; Ritieni, A.; Graziani, G.; Shahak, Y.; Forlani, M. Photo-selective hail nets affect fruit size and quality in Hayward kiwifruit. Sci. Hortic. 2012, 141, 91-97. [CrossRef]

21. Girona, J.; Behboudian, M.H.; Mata, M.; Del Campo, J.; Marsal, J. Effect of hail nets on the microclimate, irrigation requirements, tree growth, and fruit yield of peach orchards in Catalonia (Spain). J. Hortic. Sci. Biotechnol. 2012, 87, 545-550. [CrossRef]

22. Milivojević, J.; Radivojević, D.; Ruml, M.; Dimitrijević, M.; Maksimović, J.D. Does microclimate under grey hail protection net affect biological and nutritional properties of "Duke" highbush blueberry (Vaccinium corymbosum L.)? Fruits 2016, 71, 161-170. [CrossRef]

23. Jiang, Y.; Zeng, Q.; Wei, J.; Jiang, J.; Li, Y.; Chen, J.; Yu, H. Growth, fruit yield, photosynthetic characteristics, and leaf microelement concentration of two blueberry cultivars under different long-term soil pH treatments. Agronomy 2019, 9, 357. [CrossRef]

24. Whidden, A. Commercial blueberry production methods in Hillsborough County. Proc. Fla. State Hort. Soc. $2008,121,36-37$.

25. Kingston, P.H.; Scagel, C.F.; Bryla, D.R. Suitability of sphagnum moss, coir, and douglas fir bark as soilless substrates for container production of highbush blueberry. HortScience 2017, 52, 1692-1699. [CrossRef]

26. Mikulic-Petkovsek, M.; Stampar, F.; Veberic, R. Parameters of inner quality of the apple scab resistant and susceptible apple cultivars (Malus domestica Borkh.). Sci. Hortic. 2007, 114, 37-44. [CrossRef]

27. Mikulic-Petkovsek, M.; Schmitzer, V.; Slatnar, A.; Stampar, F.; Veberic, R. Composition of Sugars, Organic Acids, and Total Phenolics in 25 Wild or Cultivated Berry Species. J. Food Sci. 2012, 77, C1064-C1070. [CrossRef]

28. Mikulic-Petkovsek, M.; Slatnar, A.; Stampar, F.; Veberic, R. The influence of organic/integrated production on the content of phenolic compounds in apple leaves and fruits in four different varieties over a 2-year period. J. Sci. Food Agric. 2010, 90, 2366-2378. [CrossRef]

29. The R Project for Statistical Computing. R: A Language and Environment for Statistical Computing; R Core Team: Vienna, Austria, 2021.

30. Retamal-Salgado, J.; Bastías, R.M.; Wilckens, R.; Paulino, L. Influence of microclimatic conditions under high tunnels on the physiological and productive responses in blueberry 'O'Neal'. Chil. J. Agric. Res. 2015, 75, 291-297. [CrossRef]

31. Ogden, A.B.; van Iersel, M.W. Southern highbush Blueberry production in High Tunnels: Temperatures, development, yield, and fruit quality during the establishment years. HortScience 2009, 44, 1850-1856. [CrossRef]

32. Tamada, T.; Ozeki, M. Evaluation of Blueberry Types and Cultivars for Early Market Production in Japan Using Unheated Plastic House Culture. Int. J. Fruit Sci. 2012, 12, 83-91. [CrossRef]

33. Moon, J.W., Jr.; Hancock, J.F., Jr.; Draper, A.D.; Flore, J.A. Genotypic differences in the effect of temperature on $\mathrm{CO}_{2}$ assimilation and water use efficiency in blueberry. J. Am. Soc. Hortic. Sci. 1987, 112, 170-173.

34. Hao, L.; Guo, L.; Li, R.; Cheng, Y.; Huang, L.; Zhou, H.; Xu, M.; Li, F.; Zhang, X.; Zheng, Y. Responses of photosynthesis to high temperature stress associated with changes in leaf structure and biochemistry of blueberry (Vaccinium corymbosum L.). Sci. Hortic. 2019, 246, 251-264. [CrossRef]

35. Paulitz, T.C.; Belanger, R.R. Biological control in greenhouse systems. Annu. Rev. Phytopathol. 2001, 39, 103-133. [CrossRef] 
36. Milivojević, J.; Radivojević, D.; Nikolić, M.; Maksimović, J.D. Changes in fruit quality of highbush blueberries (Vaccinium corymbosum) during the ripening season. Acta Hortic. 2016, 1139, 657-664. [CrossRef]

37. Cantliffe, D.J. Pre- and Postharvest Practices for Improved Vegetable Transplant Quality. Horttechnology 2018, 3, 415-418. [CrossRef]

38. Yang, Q.; Liu, E.; Fu, Y.; Yuan, F.; Zhang, T.; Peng, S. High temperatures during flowering reduce fruit set in rabbiteye blueberry. J. Am. Soc. Hortic. Sci. 2019, 144, 339-351. [CrossRef]

39. Lang, A. Xylem, phloem and transpiration flows in developing apple fruits. J. Exp. Bot. 1990, 41, 645-651. [CrossRef]

40. Santos, B.M.; Salame-Donoso, T.P. Performance of southern highbush blueberry cultivars under high tunnels in Florida. Horttechnology 2012, 22, 700-704. [CrossRef]

41. Retamales, J.B.; Montecino, J.M.; Lobos, G.A.; Rojas, L.A. Colored shading nets increase yields and profitability of highbush blueberries. Acta Hortic. 2008, 770, 193-197. [CrossRef]

42. Duarte, C.; Guerra, M.; Daniel, P.; Camelo, A.L.; Yommi, A. Quality changes of highbush blueberries fruit stored in CA with different $\mathrm{CO}_{2}$ levels. J. Food Sci. 2009, 74, S154-S159. [CrossRef] [PubMed]

43. Ehlenfeldt, M.K.; Martin, R.B. A survey of fruit firmness in highbush blueberry and species-introgressed blueberry cultivars. HortScience 2002, 37, 386-389. [CrossRef]

44. Zorenc, Z.; Veberic, R.; Stampar, F.; Koron, D.; Mikulic-Petkovsek, M. White versus blue: Does the wild "albino" bilberry (Vaccinium myrtillus L.) differ in fruit quality compared to the blue one? Food Chem. 2016, 211, 876-882. [CrossRef]

45. Skrovankova, S.; Sumczynski, D.; Mlcek, J.; Jurikova, T.; Sochor, J. Bioactive compounds and antioxidant activity in different types of berries. Int. J. Mol. Sci. 2015, 16, 24673-24706. [CrossRef]

46. Li, X.; Li, C.; Sun, J.; Jackson, A. Dynamic changes of enzymes involved in sugar and organic acid level modification during blueberry fruit maturation. Food Chem. 2020, 309, 125617. [CrossRef] [PubMed]

47. Zorenc, Z.; Veberic, R.; Stampar, F.; Koron, D.; Mikulic-Petkovsek, M. Changes in berry quality of northern highbush blueberry (Vaccinium corymbosum L.) during the harvest season. Turk. J. Agric. For. 2016, 40, 855-864. [CrossRef]

48. Lobos, G.A.; Callow, P.; Hancock, J.F. The effect of delaying harvest date on fruit quality and storage of late highbush blueberry cultivars (Vaccinium corymbosum L.). Postharvest Biol. Technol. 2014, 87, 133-139. [CrossRef]

49. Almutairi, K.F.; Bryla, D.R.; Strik, B.C. Potential of deficit irrigation, irrigation cutoffs, and crop thinning to maintain yield and fruit quality with less water in northern highbush blueberry. HortScience 2017, 52, 625-633. [CrossRef]

50. Lobos, T.E.; Retamales, J.B.; Ortega-Farías, S.; Hanson, E.J.; López-Olivari, R.; Mora, M.L. Regulated deficit irrigation effects on physiological parameters, yield, fruit quality and antioxidants of Vaccinium corymbosum plants cv. Brigitta. Irrig. Sci. 2018, 36, 49-60. [CrossRef]

51. Jakopic, J.; Stampar, F.; Veberic, R. The influence of exposure to light on the phenolic content of "Fuji" apple. Sci. Hortic. 2009, 123, 234-239. [CrossRef]

52. Smrke, T.; Veberic, R.; Hudina, M.; Stamic, D.; Jakopic, J. Comparison of Highbush Blueberry (Vaccinium corymbosum L.) under Ridge and Pot Production. Agriculture 2021, 11, 929. [CrossRef]

53. Spiers, J.M. Substrate temperatures influence root and shoot growth of southern highbush and rabbiteye blueberries. HortScience 1995, 30, 1029-1030. [CrossRef] 